\title{
Eso que siempre nos acompaña: la evaluación escolar
}

\author{
Joshua Vazcoy Cuéllar y Luis Ángel Rosas Martínez
}

\begin{abstract}
Resumen
Somos Joshua y Ángel, dos buenos amigos que se conocieron en el bachillerato. Allí pudimos tratar con maestros que cultivaron nuestro gusto por la historia; gusto que orientó nuestra vocación y la pervivencia de nuestra amistad. Gracias a él fuimos empleados por una maestra al terminar el bachillerato y nos decidimos a estudiar la Licenciatura en Historia en la Facultad de Filosofía y Letras (FFyL) de la Universidad Nacional Autónoma de México (UNAM). En ella hemos experimentado muchas vivencias, algunas gratas y otras no tanto; vivencias que al final nos han motivado a continuar con nuestra vocación y amistad. En este artículo abordamos algo de nuestra experiencia con las diferentes formas con las que nos han evaluado los profesores universitarios, ciertas dificultades relacionadas con ellas y breves reflexiones orientadas a solucionarlas.
\end{abstract}

Palabras clave: experiencia, obligaciones, evaluación, Licenciatura en Historia, presión social.

\section{WhAT ALWAYS ACCOMPANIES US: SCHOOL EVALUATION}

\begin{abstract}
We are Joshua and Angel, good friends that met in high school. In there some teachers cultivated our liking for history. This liking has guided our vocation and has maintained our friendship. Thanks to it we were employed by a teacher at the end of high school and we decided to study a history degree on the School of Philosophy and Literature (FFyL) of the National Autonomous University of Mexico (UNAM). There we have lived many experiences, some pleasant and other not so much; experiences that in the end have motivated us to continue with our vocation and friendship. In this article we set out some of our experience with the different ways in which university teachers have evaluated us, certain problems of those ways and a brief reflection on how to solve them.
\end{abstract}

Keywords: experience, obligations, evaluation, history degree, social pressure.

DOI: http://doi.org/10.22201/codeic.16076079e.2019.v20n2.a7 


\section{Joshua Vazcoy Cuéllar}

\section{vazcoy.cuellar.joshua415f@gmail.com}

Es estudiante del sexto semestre de la Licenciatura en Historia de la fFyL de la UNAM (generación 2017). Allí presentó la ponencia que hizo en coautoría con Luis Antonio Soto García "Al fondo del pasillo. Aproximación a la experiencia en el 'Tren de las Humanidades'. 1960-2018", durante el coloquio de estudiantes De Historia contemporánea y del tiempo presente de México, organizado por el Seminario permanente de historia contemporánea y del tiempo presente de México.

Realizó el bachillerato en el plantel 5, "José Vasconcelos" de la Escuela Nacional Preparatoria (20142016). Allí participo con Luis Ángel y Aranza Pérez Sarmiento en el Programa de jóvenes hacia la investigación en humanidades, ciencias sociales y artes en el ciclo escolar 2015-2016; y obtuvo mención honorífica en la 5a. Olimpiada Universitaria del Conocimiento 2015 en el área de Historia.

Sus temas de interés son los relativos a la historia del siglo Xx, en especial la de México.

\section{Luis Ángel Rosas Martínez}

angel_rmtz@hotmail.com

Actualmente estudia los últimos semestres de la Licenciatura en Historia en la fFyL de la UNAM. Ha sido parte de varios cursos anuales, seminarios y diplomados en instituciones como el Instituto Nacional de Estudios Históricos de las Revoluciones de México, el Instituto de Investigaciones Históricas de la UNAM y la misma FFYL-UNAM.

Es egresado del plantel 5 de la Escuela Nacional Preparatoria, en donde participó en varios proyectos, entre los que se destaca el programa institucional "Jóvenes hacia la investigación en ciencias sociales y humanidades"; además de varios concursos interpreparatorianos en el área de historia organizados por la Dirección General de la Escuela Nacional Preparatoria. Entre sus temas de interés se encuentran la historia intelectual del siglo Xx en México, la historiografía y teoría de la historia, y la biografía como género historiográfico. 


\section{Una historia común}

Es difícil ofrecer una presentación de uno mismo, siempre se corre el riesgo de caer en omisiones o ser demasiado optimista. En honor a la verdad trataremos de ser justos con nuestra descripción. Somos Joshua y Ángel, buenos amigos desde hace cinco años, lo cual quiere decir que desde 2013 iniciamos este vínculo que se ha ido reforzando, entre otros motivos, por ciertos gustos y afinidades como el que tenemos por las artes, las humanidades y, sobre todo, por la historia.

El comienzo de nuestra amistad fue en la Escuela Nacional Preparatoria plantel 5 "José Vasconcelos" de la UNAM, en donde, junto con muchos otros chicos, buscamos una actividad que nos apasionara detal forma que decidiéramos dedicarnos a ella toda la vida. Sin mucha complicación, a diferencia de varios amigos, orientamos nuestra vocación e intereses hacia la carrera de historia, que está ensombrecida por los prejuicios y las tendencias de buena parte de nuestra sociedad. Pero ¿por qué nos apasionó una carrera de la que dicen que "no te va a dar de comer"? No lo sabemos, diremos que fue un llamado espontáneo que nos inquietó continuamente y nosotros lo atendimos. Además de que hemos visto que sí se puede vivir de esto; tal vez no sea fácil, pero con trabajo, esfuerzo, dedicación y con el respaldo de otros seguramente se puede.

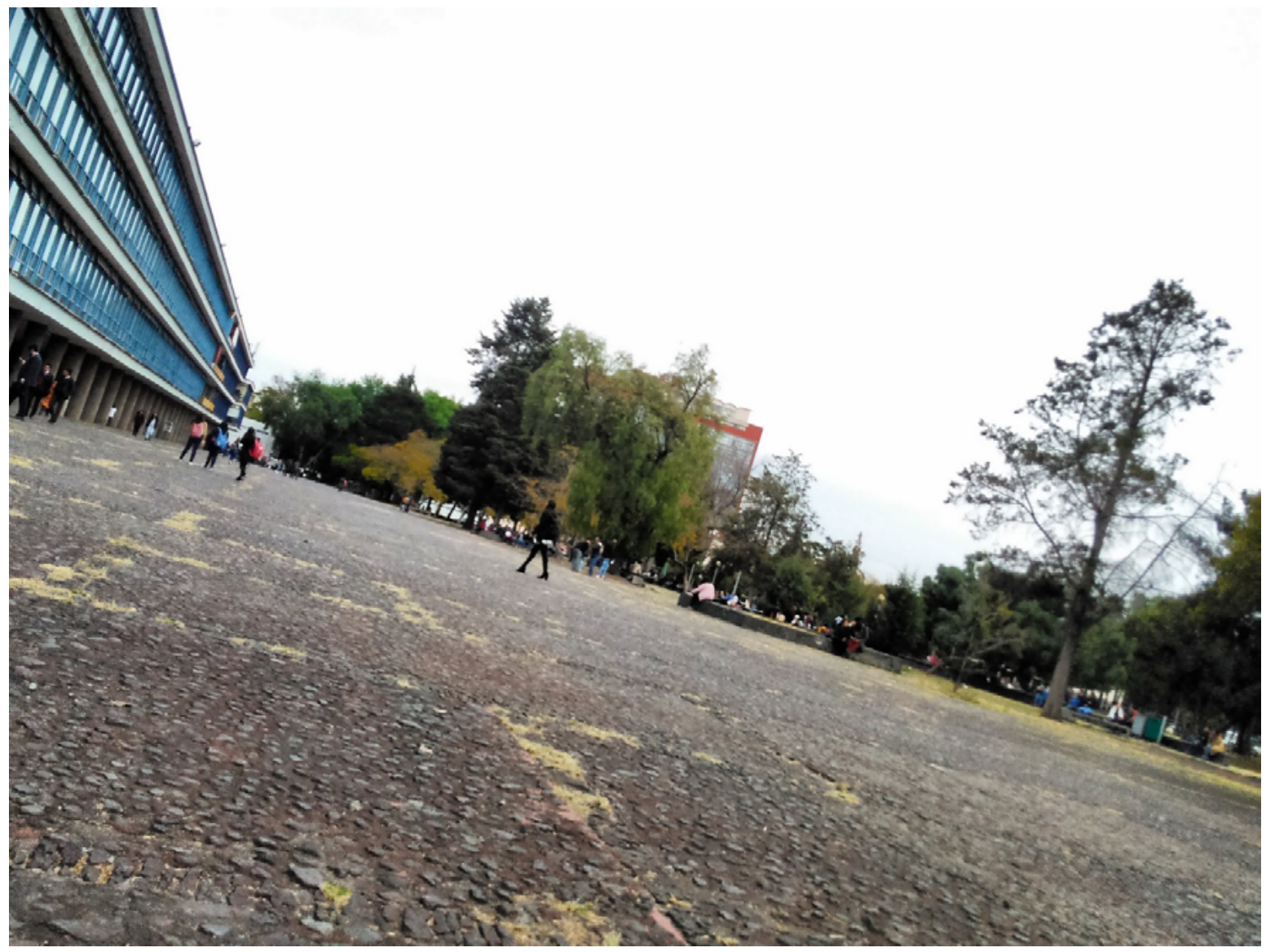


Muchas veces hemos discutido nuestra elección y en ocasiones llegamos a la conclusión de que, más allá de nuestro aparente innato gusto por la historia, influyeron varias cosas más. Entre ellas nuestra convivencia con los maestros de historia de la misma prepa de Coapa, la que también cultivamos fuera de las aulas. Conocimos al maestro Juan Manuel, severo a veces, gracioso otras tantas, crítico de su presente, con quien convivimos gozosamente durante los tres años del bachillerato. Nuestras maestras de sexto también nos orientaron: la maestra Laura, tan mesurada, sabia, graciosa y admirada por todos; Gabriela, de carácter fuerte, por el que todos le temían, pero una persona virtuosa que nos enseñó bastante. Convivimos mucho con ellas ese último año. Esas clases fueron sinceramente magistrales.

En dicho año también inició nuestra relación con la maestra de Historia de la Cultura, quien dirigió nuestro desmedido interés por el conocimiento histórico hacia algo más serio. Asimismo, lo hizo al terminar el bachillerato: fuera de las aulas nos dio la oportunidad de desarrollar las habilidades necesarias para la carrera que decidimos estudiar. Hasta la fecha mantenemos un vínculo sólido con ella, nuestra maestra Blanca Alicia. Gracias a ella pudimos escribir estas líneas sobre nuestra experiencia con la evaluación universitaria.

Al escribir estas líneas nos concientizamos de que las vivencias que hemos tenido durante la primera mitad de la carrera en Historia, las que diariamente tuvimos con los maestros, compañeros, las tareas y exámenes en la Facultad de Filosofía y Letras de la UNAM, giran en torno a la educación. Parece obvio cuando lo reflexionamos, pero como no lo habíamos hecho previamente no lo supimos hasta ahora. Nunca las pensamos con atención debido a que no tuvimos motivos para hacerlo, ni siquiera lo extenuante que puede ser el estudiar en la Facultad nos motivó a ello; aunque sí sabemos que cursar la primera mitad de la carrera no fue fácil, como lo piensan muchos compañeros, amigos y familiares: que en estas carreras humanistas sólo hay que "pasársela suave". ¡Claro que no!

\section{¿Fue buena idea elegir la carrera de Historia?}

Desde la primera clase en la licenciatura vimos que las cosas eran harto distintas. Escuchar a ciertos profesores fue como una lluvia torrencial de conocimientos que nos empapó de inmediato. ¡La prepa había quedado atrás! No pasó mucho tiempo para que dimensionáramos el nivel de rigor que exigían los maestros, la complejidad de los temas, de los interminables trabajos que debíamos entregar y de las diversas formas de evaluar el conocimiento histórico. Esa sensación de enfrentarse a algo que te sobrepasa es lo que se siente durante todo el semestre.

Sin duda ser parte de la licenciatura implica un privilegio, pero como consecuencia (no siempre negativa) debemos afrontar una gran carga de trabajo que con el tiempo nos formará como historiadores. El trabajo no se reduce a concentrarnos en lo que exponen los maestros en las aulas, sino que continúa 
en el hogar con la realización de lecturas, ensayos de distintas cuestiones, preparación de exposiciones y trabajos que se deben construir a lo largo del semestre con la asesoría de los profesores.

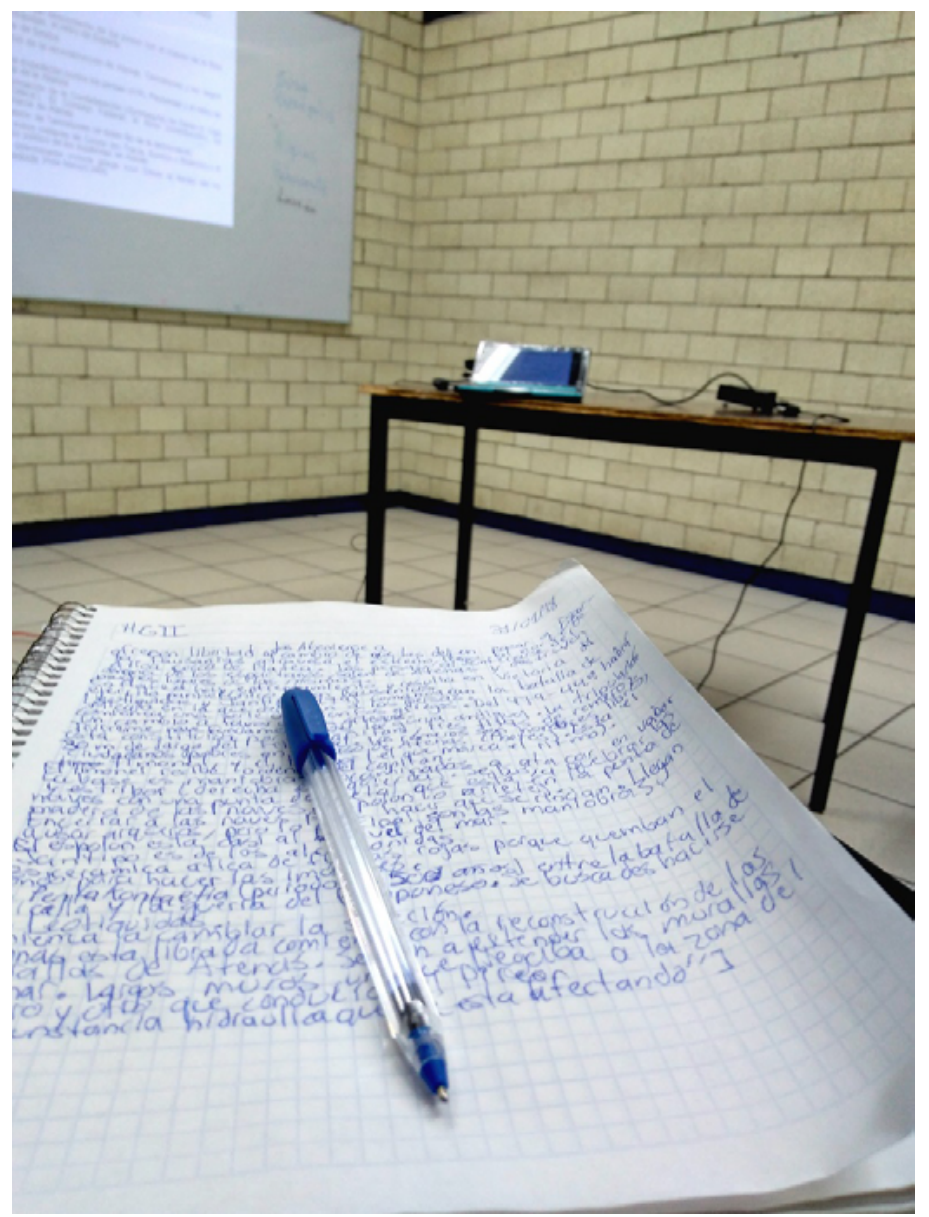

El grado de exigencia de estos trabajos depende, concretamente, de factores como la concepción de historia que tenga el profesor y del tipo de asignatura, pues no es lo mismo una que tenga por objeto revisar la historia de los mayas del clásico temprano, que otra cuyo fin sea reflexionar la naturaleza del conocimiento histórico o la utilidad de éste en las sociedades contemporáneas. También depende del tipo de profesor, pues hay unos que están convencidos de que el rigor y la exigencia deben ser parte del proceso de formación de los universitarios; en cambio, otros piensan que es mejor que el propio estudiante marque su ritmo de aprendizaje, que descubra lo que le interesa en este gran campo de la historia.

De manera cotidiana experimentamos las diversas maneras de enseñar y evaluar de cada profesor. Por su exigencia y ciertas circunstancias, a veces nos satisfacen y otras, nos consumen. Sin embargo, después de todo, tales actividades y tareas son más un gozo que un hastío. Por ejemplo, disfrutamos escuchar a un sabio profesor como Miguel Soto, pues al hablar del siglo xix mexicano nos lleva a imaginarlo con un realismo tal que parece que estamos ahí viviendo la historia; leer una obra del magnífico Edmundo O' Gorman; examinar un descolorido e interesante documento; contestar un examen; y escribir un ensayo. O cuando se entrega un trabajo, se acaba un curso o el semestre; pero cuando sucede esto, más que gozo, se siente alivio de haber acabado con las obligaciones escolares.

\section{Nuestra experiencia con la evaluación universitaria}

Como estudiantes estamos obligados a hacer trabajos de calidad para conseguir una buena calificación en la evaluación y así evitarnos complicaciones durante la licenciatura. En nuestra facultad los profesores nos evalúan con exámenes, reseñas, reportes de lectura, ensayos, proyectos de investigación, exposiciones, videos, podcasts, participaciones en clase con base en lecturas, entre otros. Estas tareas nos las exigen al inicio, a mediados, al final o durante todo el curso; cada clase, semana o mes..., es decir, no paramos hasta que acaba el semestre. 
La tendencia es hacer uno o varios exámenes y el último de éstos puede ser el más difícil porque no está hecho bajo las mismas pautas que los anteriores, ya que es un examen planeado para evaluar de forma global los conocimientos y habilidades que el profesor espera que hayan aprendido los estudiantes a lo largo del curso. Esto aplica también para los profesores que evalúan con un solo examen o trabajo final. Así lo hacen por sus infinitas ocupaciones, ya que laboran en varias instituciones que no los dejan evaluar con muchas actividades. No obstante, el examen o trabajo final lo revisan minuciosamente, llegan a señalar hasta el más pequeño error ortográfico. Sin embargo, consideramos que esa manera de evaluar no es la más adecuada ya que no incluye la mayoría del trabajo que está detrás del examen o escrito final.

No por ello estamos en contra de la manera en que dan clase, ya que son magistrales. Su grandiosa sabiduría se distingue en cada sesión cuando exponen complejos temas con una amena claridad; por lo que tomar nota se vuelve esencial para aprobar. Es difícil seguirles el ritmo por su profunda y un tanto rápida exposición: en una clase pueden tocar varios temas. Entonces, no sólo apuntamos las ideas principales, sino muchas más, porque nos parecieron interesantes. Nuestro apunte termina siendo un lago de información del que es difícil pescar las ideas principales. Esta situación nos complica contestar un examen o realizar la actividad acordada. Usualmente, los exámenes los contestamos con lo que recordamos de las lecturas, de lo que dijo el profesor y con nuestro discernimiento. Aunque hay exámenes que se pueden contestar sólo con lo recordado de las clases y lecturas, esto varía de acuerdo a la exigencia del tema que se trate.

Contestar dos cuartillas y media dentro del salón con otros cuarenta compañeros que también están cansados y estresados no es el mejor ambiente. Así sucede por las circunstancias previas: es común que el día en que se hace un examen también se deba realizar otros o entregar tareas. Hay uno que otro maestro que para cada clase pide una actividad y eso contribuye a no tener tiempo suficiente para estudiar lo requerido de la mejor manera. Además de que el tiempo que nos dan para contestar el examen (de una a dos horas) no es suficiente para hacerlo concienzuda, tranquila y reflexivamente. Nos parece insuficiente debido a la costumbre que tenemos de recordar lo que no nos están preguntando, por lo que debemos recapitular varias cosas para contestar con precisión. Mejor dicho, no nos acordamos porque normalmente las preguntas no están hechas para que contestes el dato preciso, sino que te preguntan cómo entiendes determinados temas o cómo los conciben los autores cuyas obras se leyeron durante todo el curso. Por lo que es necesario, para contestar de la mejor manera, recordar y tener la noción de varias cuestiones.

Ante dichas circunstancias a las que se enfrenta el estudiante, además de las que tiene que vivir cotidianamente, es esencial habituarse a desvelarse o a no dormir para seguir el ritmo del semestre. Hábito continuo porque además se debe investigar, actividad primordial para hacer cualquier tarea, en especial 
Imagen: Facultad de Filosofía y Letras, UNAM (crédito: Morgana Carranco) para los proyectos o trabajos finales, ya que éstos consisten en temas inmensos y es fundamental basarse en lo que han escrito otros para idear cómo hacerlos y evitar planteamientos errados.

Es cierto que examinar los textos de otros es el pan de cada día de la carrera de historia y seguramente de cualquier otra, no lo sabemos a ciencia cierta. Dicho ejercicio nos sirve no sólo para los trabajos finales, sino también para los que van pidiendo cotidianamente: reseñas, reportes de lectura, pequeños ensayos, discusión de lecturas y exposiciones en clase. En estas actividades se trabaja sobre los planteamientos de los autores en lugar de usarlos como fundamento de nuestras ideas, lo que requiere de un estudio minucioso del texto.

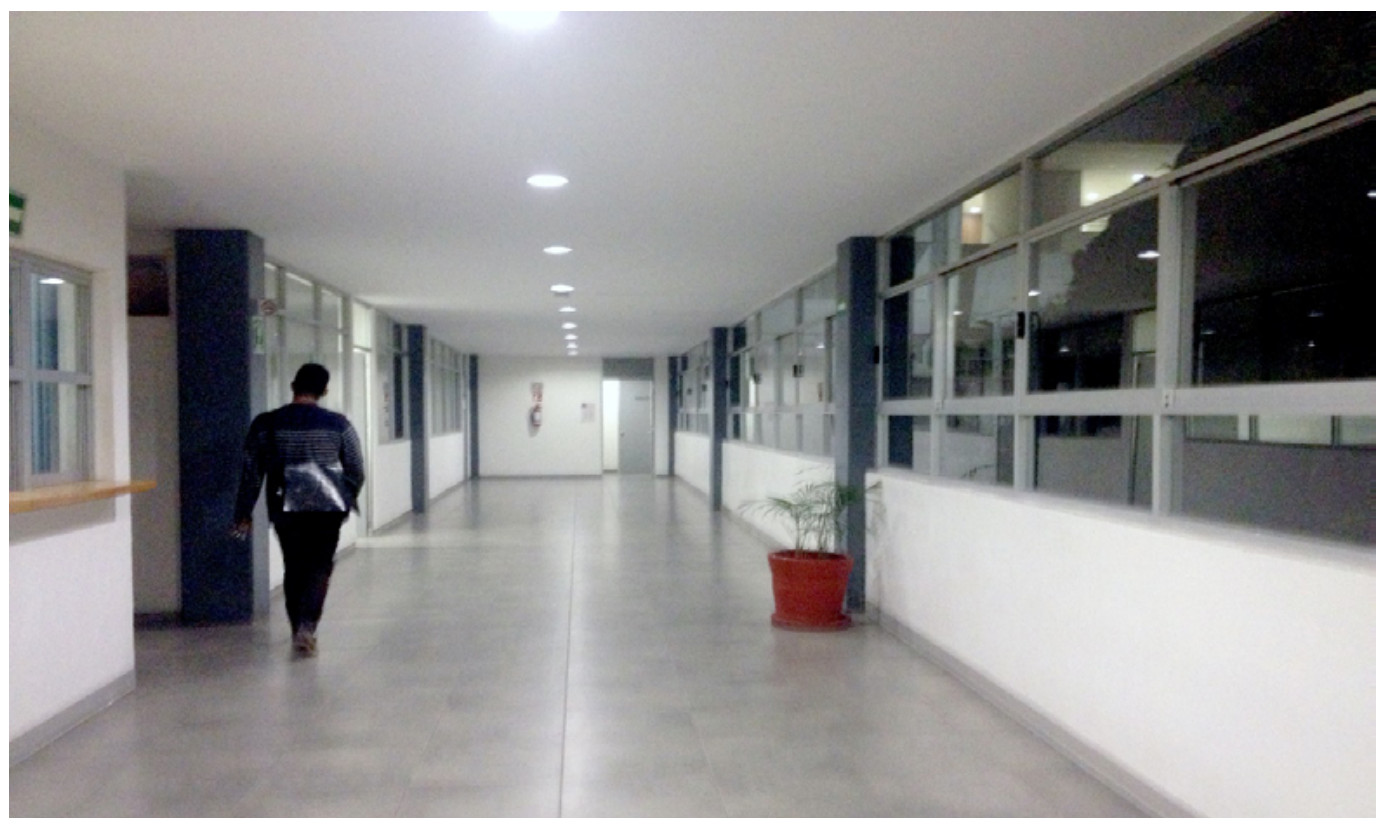

Hay compañeros que se enfocan en las generalidades de los textos, a nosotros nos es más práctico concentrarnos en las particularidades para escribir lo más pronto posible. Siempre queremos dedicarles poco tiempo a esas actividades porque tenemos otras que resolver, ya que es normal que se acumulen, además de que hay que afrontar las distintas situaciones en nuestras vidas. ¿Nuestras? Cuando irrumpen las circunstancias dejan de ser nuestras para ser parte de las de familiares, amigos, maestros y compañeros. Al participar en clase estás dando algo de tu vida al grupo: una interpretación de lo leído, un complemento de lo que otro compañero dijo o de lo que expuso el profesor. Sin embargo, en muchas ocasiones se trata de reiteraciones, contestaciones y, pocas veces, rebatimientos.

Esta atmósfera nos agobia porque cuando asistimos a clases, como podrán imaginar, ya estamos agotados por el semestre y otras situaciones. Además de que casi toda nuestra vida hemos tenido pena de hablar en público por miedo a que nuestra opinión no sea bien recibida, o a que lo que podamos 
decir sea impertinente. Ese temor se debe, en parte, a que las opiniones de los compañeros pueden confundirnos, ya que cada quien expresa sus ideas de una singular manera. En ciertas ocasiones, sus puntos de vista nos hacen dudar de que si lo que creíamos era cierto, entonces, empezamos a reformularlo, a veces, intentando integrar todo lo dicho en una "sesuda" respuesta que no siempre llega, por eso callamos.

\section{Reflexiones finales}

Hemos hablado de algunos rasgos de nuestra experiencia respecto a la evaluación, los que dan una idea del ambiente en el que nos movemos. Como se ha descrito en ocasiones nuestro contexto se torna desgastante a un grado casi indescriptible, pero bien vale la pena por los resultados, ya que al final del día se convierten en granos de arena que coadyuvan a nuestra formación. Lo que nos falta es abordar los momentos agradables de las actividades con las que nos han evaluado, ahora es tiempo de mencionar algunos.

En aquel instante en que estamos respondiendo una pregunta, a veces recordamos y visualizamos al profesor de la materia cuando nos dijo algo útil para contestar; asimismo, recordamos el contenido de las lecturas que nos pueden ser de utilidad. Ese momento es placentero porque nos abstraemos de las presiones del examen y nos concientizamos de saberes que no imaginábamos que poseíamos, el problema es que uno puede divagar si deja que se pierda la conciencia en las imágenes mentales, aunque esto es de utilidad para responder lo que se desconoce en aquel instante. Confesamos que tardamos mucho en pensar las respuestas y redactarlas, tanto así que acabamos de contestar el examen después del tiempo que nos dieron, por lo que el adjunto o el mismísimo profesor tiene la amabilidad de esperarnos más tiempo, lo normal es que no seamos los únicos que faltan de contestar. En esos últimos minutos es cuando nos apuramos a responder las preguntas.

Las demás actividades son parecidas a ese placentero o apurado momento en el que buscamos responder una pregunta, lo que varía es la duración y forma del trabajo, de la investigación y del estudio de lo hallado, duración que depende de las costumbres del estudiante, del tiempo otorgado por el profesor y en general de lo necesario para escribir, por ejemplo, un ensayo o una reseña. Estas actividades son más enriquecedoras para el aprendizaje que los exámenes, es más fácil comprender los temas al realizarlas. 


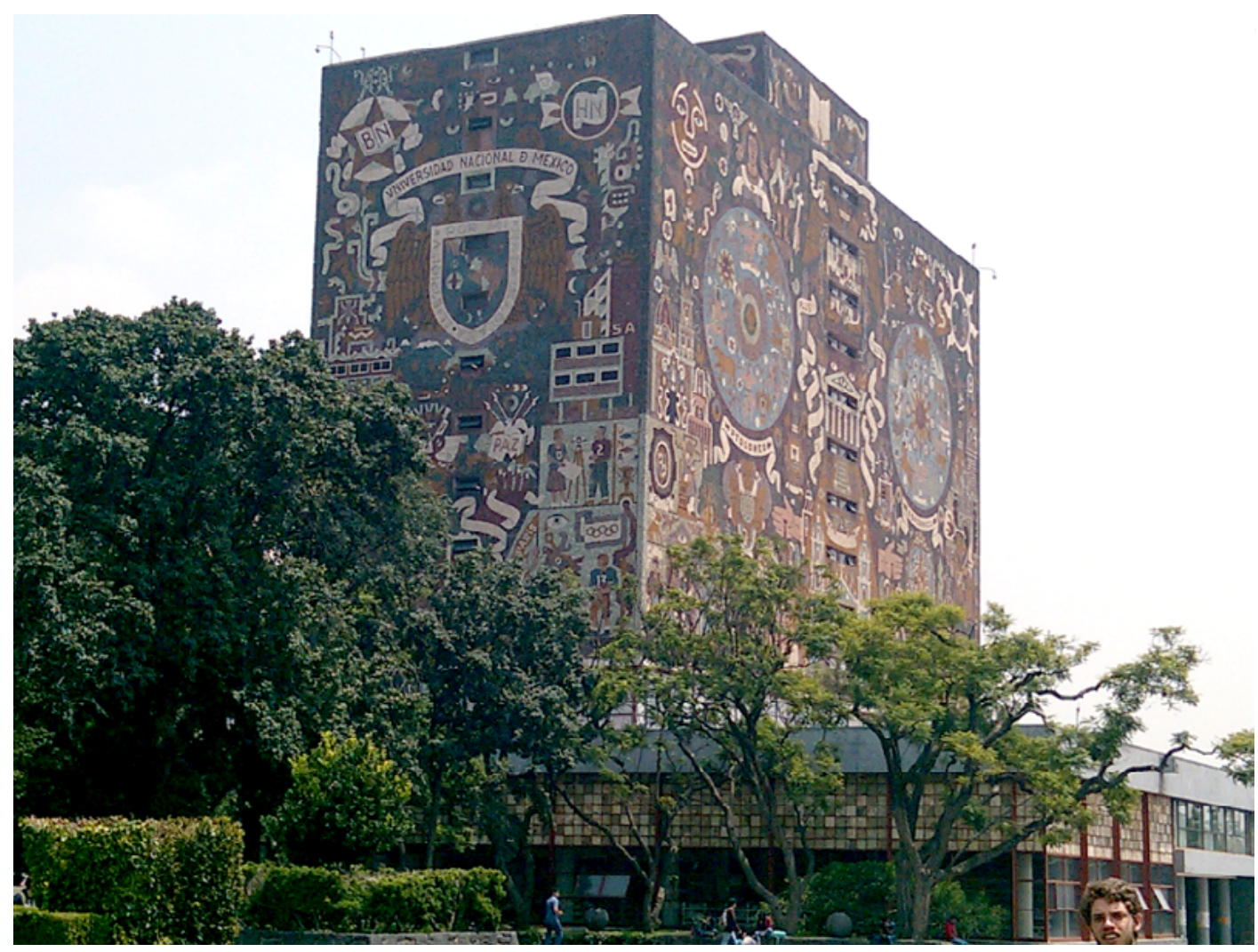

Lo cierto es que aprender cuesta mucho y dependiendo de las circunstancias puede costar demasiado, es por ello que cansa. Más aún porque muchos profesores dejan bastante trabajo, por lo que es más complicado aprender de todo ello. Sin embargo, así lo hacen para que adquieras nociones de la complejidad de los temas que se están estudiando, no para que busques comprenderlos exhaustivamente. Aun así, nos es difícil dejar de intentar comprender lo que se estudia, creemos que si no se intenta el estudiante puede cursar la licenciatura aprendiendo poco; si no se estudia detenidamente lo poco de los grandes temas que vemos en la facultad, el estudiante puede tender a no aprender lo necesario para constituir una incipiente noción de ellos.

La verdad es que la duración del semestre no es suficiente para estudiar de manera pausada todos los temas implicados en el trabajo que dejan los profesores. Si lo haces, como nos ha pasado, te condenas a dejar de lado cierta tarea y a perder una buena calificación. Estudiar detenidamente fue una costumbre que cultivamos en la prepa, debido a que disfrutábamos de tiempo de sobra para estudiar lo obligatorio y lo que nos gustaba. En la facultad no disfrutamos de esto, más que nada, debido a otras circunstancias: cuando entramos a la facultad empezamos a contraer otras obligaciones, fuimos empleados, nos responsabilizamos de más quehaceres con la familia y practicamos cierta militancia. Vivimos la necesidad de organizarnos mejor, de distribuir nuestros tiempos, de renunciar a las actividades recreativas que solíamos hacer. Aun así, la exigencia de la facultad es la más grande, le dedicamos mucho tiempo a estudiar. 
Como en cualquier actividad humana, son las circunstancias que viven día a día los profesores, estudiantes y demás integrantes de la facultad las que repercuten en lo que se aprende y evalúa. Unos no tienen problemas porque sus circunstancias los favorecen, mientras que a otros les es más difícil hacer llevaderas las tareas para evaluar o ser evaluados. En realidad, la situación no es tan tajante, sino que existen matices, ya que las circunstancias son cambiantes: a veces favorecen y otras veces no, como nos ha pasado. Es esta variabilidad lo que complica aprender y hacer lo necesario para evaluar y ser evaluados.

Es también por dicha situación que lo relacionado a la evaluación ha sido criticado y estudiado por funcionarios, investigadores, profesores y estudiantes. Sin embargo, suponemos que diversas circunstancias no han permitido que sus propuestas sean aprovechadas por las instituciones educativas y por lo que el ámbito de la evaluación no ha podido armonizar con las necesidades consecuentes de las circunstancias variables de quienes constituyen dichas instituciones.

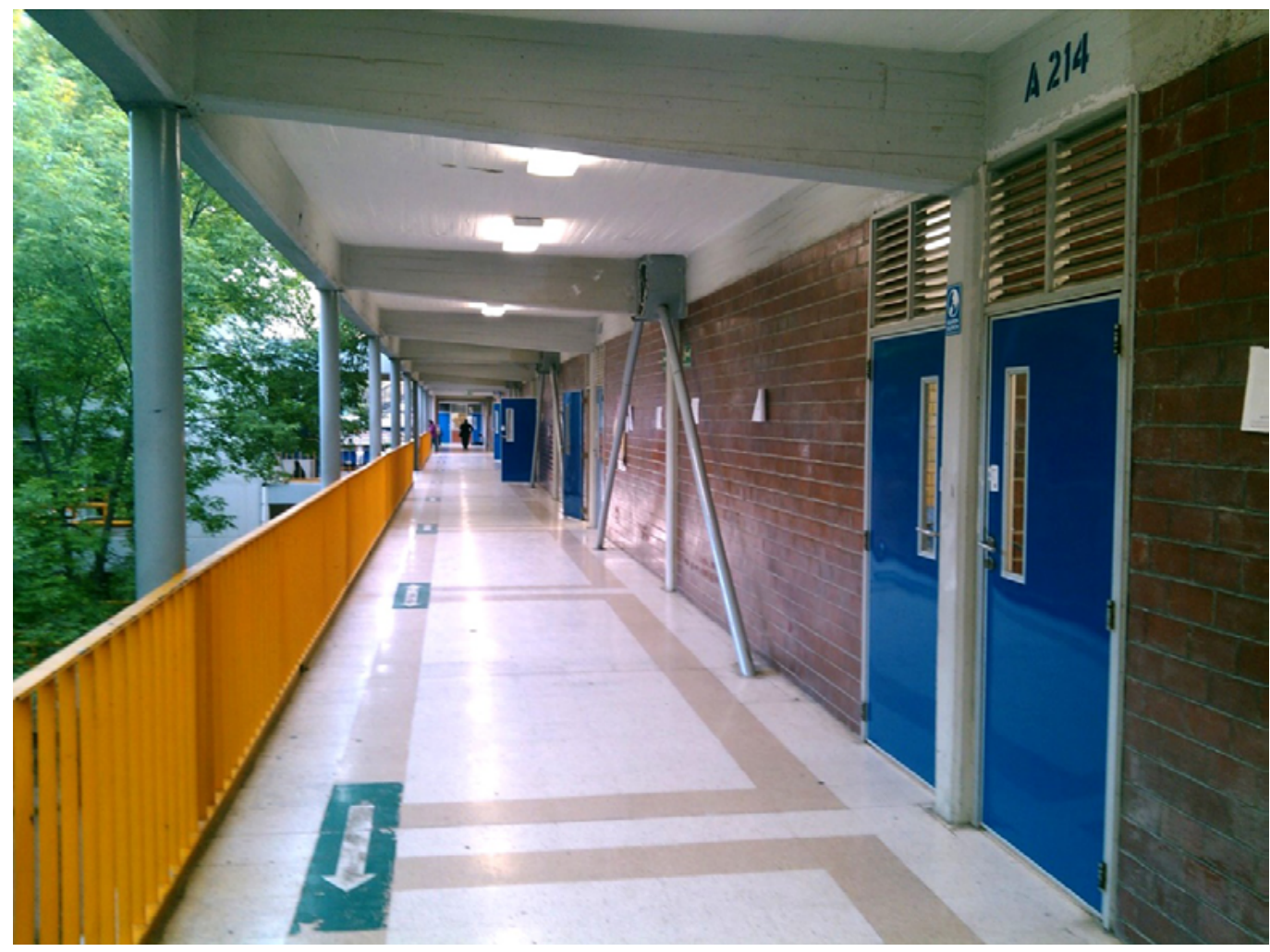

¿Qué podemos hacer para propiciar la armonía que se necesita? Antes que nada, creemos que profesores y estudiantes deben dialogar más entre ellos para saber cuáles son esos problemas comunes, trabajar en conjunto y disminuirlos. Debido a lo que hemos vivido en nuestra facultad, sabemos que no todos los profesores pueden dialogar entre ellos sobre sus problemas; de igual manera, que los estudiantes no siempre dialogan entre sí al respecto. Además de que no 
todos los estudiantes y profesores han construido los lugares de confianza para dialogar mutuamente, a pesar de que se ven de manera cotidiana en la facultad. Entonces, ambos grupos debemos conocernos mejor para planear soluciones, apoyarnos en lo que ya han dicho otros en relación a nuestros problemas y organizarnos para impulsar acciones que promuevan dicha armonía.

Lo anterior suena irrealizable por la diversidad que existe en las comunidades de la facultad, lo que hace que no todos estén de acuerdo en las soluciones. Sin embargo, se debe comprender al otro para que se dialogue de tal forma que sea posible priorizar los problemas y en consecuencia se hagan los consensos necesarios para poder resolverlos. Esto sería benéfico tanto para nuestra facultad como para el resto de las instituciones que están en Ciudad Universitaria debido a que muchos de los problemas de la unAm son los mismos para todas sus facultades y escuelas, ya que compartimos los mismos espacios. De la misma manera, por tratarse de lugares públicos ubicados en la Ciudad de México, sufrimos de los problemas que afectan a los citadinos.

Muchas veces, es sencillo identificar los problemas que nos aquejan en las circunstancias que vivimos cotidianamente, lo difícil es solucionarlos. En general, sabemos ciertas formas de resolverlos, pero cada manera tiene una desventaja $y$, por lo tanto, hay que esforzarse para tener la posibilidad de solucionarlos. Sabemos que hay asuntos que se pueden resolver de inmediato, sin embargo, los problemas sociales son diferentes: aunque parezcan diminutos, en realidad, constituyen una cuestión mayor.

Un ejemplo de problema social es el siguiente. Un estudiante vive en la zona de Aragón de la Ciudad México, todas las mañanas después de tomar clases en la ffy L debe ir a trabajar a un taller mecánico próximo a su casa hasta la noche, por lo que constantemente reprueba materias. La solución para que deje de reprobar es que ya no trabaje en el taller, sin embargo, sus padres no lo apoyan económicamente en sus estudios, por lo que no podría dejar de trabajar. O podría conseguir una beca, pero como adeuda materias no se la darían, además de que en la fryı están muy limitadas.

Como vimos en el ejemplo anterior, lo que parece un problema individual en realidad es uno social porque está relacionado con instituciones como la familia y la facultad. Si quisiéramos indagar más al respecto veríamos que el problema de las becas está condicionado por el presupuesto de la facultad y otras instituciones que forman parte del Estado. En realidad, los problemas sociales están vinculados y como éstos suceden en ciertas circunstancias, éstas también se relacionan (Bourdieu, 1997). Así, los problemas que rodean a la evaluación están igualmente conectados. 
Foto: Torre II de Humanidades, UNAM (crédito: Morgana Carranco)

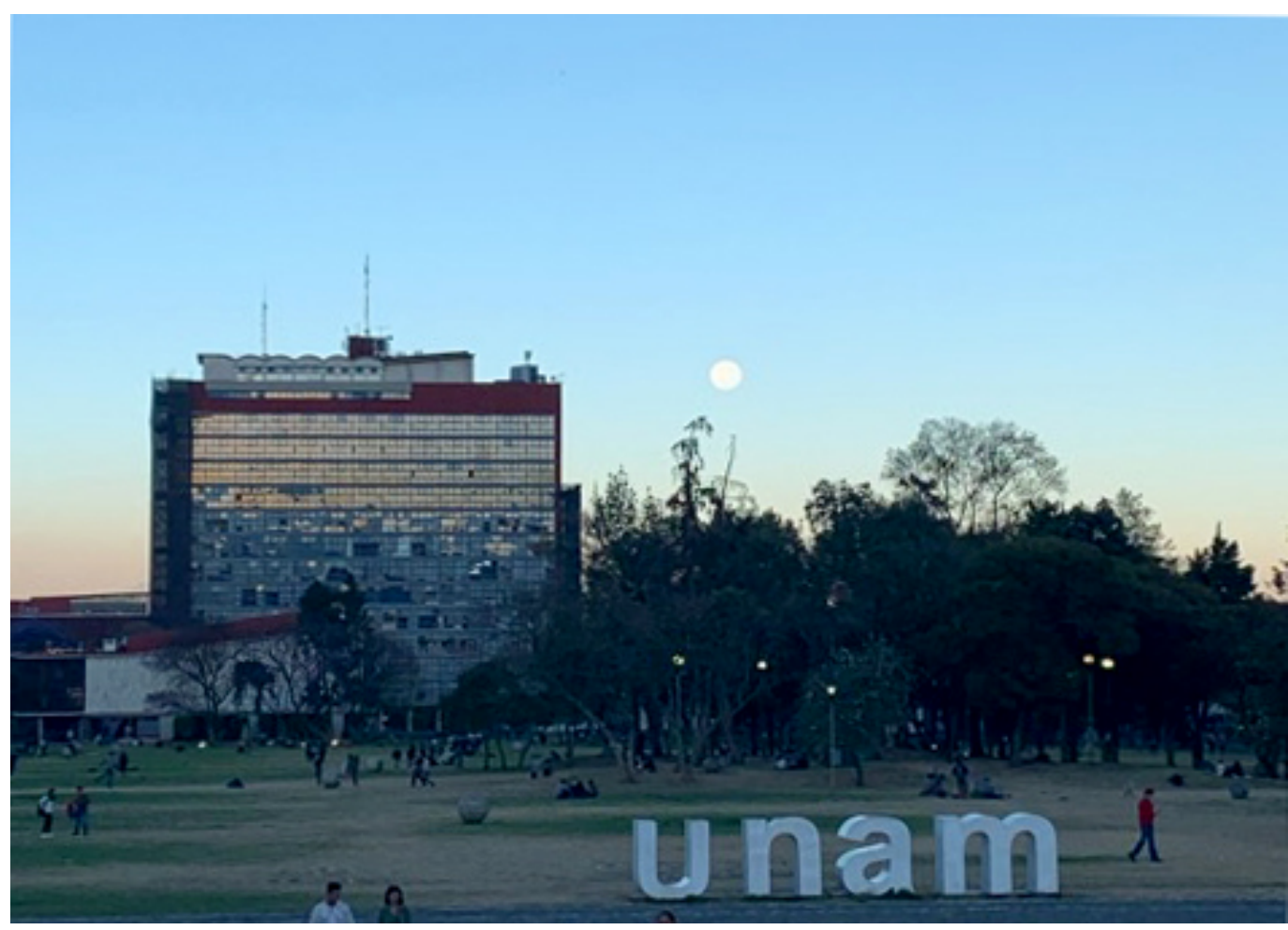

\section{Breves recomendaciones}

¿Cómo podemos, entonces, erradicar los problemas de evaluación? Por lo que hemos vivido, creemos que hay que empezar acostumbrándonos a actuar de una manera benéfica con nosotros, evitando aquellas acciones que nos perjudican y que realizamos de manera constante; por ejemplo, navegar mucho tiempo en las redes sociales o ver demasiados videos en línea; tener malos hábitos alimenticiosy de estudio; dedicarle poco tiempo a las actividades académicas por entretenernos con otras cosas; y violentar de una u otra manera a los demás. Creemos que, al evitar estas acciones perjudiciales, estos vicios, seremos humanos que tenderán hacia las acciones benéficas, a las virtudes; por ejemplo, al utilizar los recursos digitales para mejorar el aprendizaje y estar informado de nuestro presente, al realizar las actividades con más empeño y al respetar a los demás.

Muchos de los puntos que se han tratado en este relato, como la evaluación, el aprendizaje y otros, han sido abordados desde distintos ángulos por estudiosos de la pedagogía, la psicología educativa y la filosofía. No queremos poner punto final a este pequeño ensayo sin añadir, aunque sea un mínimo listado de obras que pueden ser una guía inicial para todo el que se interese por investigar algunas de las cuestiones aquí tratadas. 


\section{Referencias y bibliografía recomendada}

- Álvarez Méndez, J. M. (2001). Evaluar para conocer, examinar para excluir. Madrid: Morata.

* Díaz Barriga Arceo, F. (1998). Una aportación a la didáctica de la historia. La enseñanza-aprendizaje de habilidades cognitivas en el bachillerato. Perfiles Educativos, núm. 82, octubre y diciembre. Recuperado de: http://www.redalyc.org/ pdf/132/13208204.pdf.

* González Mangramé, I. (1993). La enseñanza de la historia en el bachillerato: la visión de los alumnos (tesis de doctorado, Universidad de Barcelona-Lleida). Recuperado de: http://www.tdx.cat/bitstream/handle/10803/8224/TIGM4de4. pdf? sequence $=4$.

- Salinas, D. (2002). Mañana examen. Barcelona: Grao.

* Sánchez Quintanar, A. (1993). El sentido de la enseñanza de la historia. Tempus. Revista de Historia de la Facultad de Filosofía y Letras, 1, otoño, pp. 173-184.

* Seisz R. y Merchán Iglesias, D. (2006). Enseñanza, examen y control: Profesores y alumnos en la clase de Historia. Biblio 3w, Revista Bibliográfica de Geografía y Ciencias Sociales, Universidad de Barcelona, XI (680). Recuperado de: http://www. ub.es/geocrit/b3w-680.htm.

* Vargas, B. A. y Cruz, M. (2018). ¿Cómo evaluamos el aprendizaje de la Historia? Experiencias y reflexiones. Revista Digital Universitaria (RDU), vol. 19, núm. 6 noviembre-diciembre. DOI: $\quad$ http://doi.org/10.22201/codeic.16076079e.2018. v19n6.a9.

* Bourdieu, P. (1997). Razones prácticas. Sobre la teoría de la acción. Barcelona: Anagrama.

\section{Cómo citar este artículo}

* Vazcoy Cuéllar, Joshua y Rosas Martínez, Luis Ángel (2019). Eso que siempre nos acompaña: la evaluación escolar. Revista Digital Universitaria (RDU). Vol. 20, núm. 2. DOI: http://doi.org/10.22201/codeic.16076079e.2019.v20n2.a7 